\title{
Intramedullary Mature Teratoma of Cervical spine in an Infant: a rare case report
}

\author{
Rakesh Kumar ${ }^{1}$, Amit Chanduka ${ }^{2}$, Devendra Purohit ${ }^{3}$, \\ Radhe Shyam Mittal ${ }^{4}$, Ronyl Kaushal ${ }^{5}$
}

Sawai Man Singh Medical College, Jaipur, Rajasthan, India

${ }^{1}$ Registrar, Department of Neurosurgery

${ }^{2}$ senior Registrar, Department of Neurosurgery

${ }^{3}$ Professor, Department of Neurosurgery

${ }^{4}$ Professor \& Head Department of Neurosurgery

${ }^{5}$ senior Registrar, Department of Neurosurgery

\begin{abstract}
Spinal Teratomas are rare tumor and cervical intramedullary location in infancy still rarer. Only eleven cases of cervical intramedullary teratoma in pediatric patients is reported in available literature $(1,11)$.We are reporting a case of an infant presenting with cervical mature teratoma with associated dysraphism, adding the next in this rare case series. Arising as a result of dysembryogenesis, these lesions by virtue of their content are difficult to diagnose preoperatively. Heterogeneous intensities on MRI produced by intralesional lipomatous and osseous elements are helpful but rarely enough to diagnose the tumor. Histology is confirmatory. Mature teratomas generally have good prognosis and a timely intervention can prevent further neurological deterioration. However a strict clinical and radiological follow up is recommended.
\end{abstract}

Key words: Intramedullary, Spinal tumour, Teratoma.

\section{Introduction}

Teratomas involving the central nervous system are rare and account for approximately $0.1-0.5 \%$ of all spinal tumors $(5,10)$. Pediatric intramedullary spinal teratomas are still rarer, excluding the sacro-coccygeal form often seen in neonates. The majority of these have been described in the literature as isolated case reports. $(3,13)$ By definition, they are tumors of pleuripotent cells derived from all 3 germ cell layers and recapitulate normal organogenesis. Broadly, they are classified as mature, immature and malignant. These lesions are rare and their uncertain clinical behavior makes diagnosis and management a difficult task. As teratomas are rarely suspected preoperatively, the diagnosis of teratoma is usually made at the time of pathological assessment. Radiology is helpful in ascertaining nature of the lesion but is not 
diagnostic. Histopathology is the gold standard for diagnosis. Here we report a case of cervical intramedullary teratoma associated with spinal dysraphism in an infant.

\section{Case Report}

An 11 month old male child presented with swelling in cervical region, opposite C6-C7 vertebral level (Figure 1). There was no history of delayed milestones or any history suggestive of urinary or faecal incontinence. General physical examination was unremarkable except a pedicled firm swelling in cervical region. No other cutaneous stigmata of spinal dysraphism seen along the spine. Fontanellae were open and not bulging. Neurological examination revealed no sensory-motor deficits and normal bowel bladder function for the age. On X-ray of cervical spine posterior arch elements of C6 and C7 vertebrae were deficient in midline. MRI showed a solid cystic extra cutaneous lesion against C6-7 vertebral level pedicled to the dura at C6 level. Two intradural cystic lesions and one heterogeneous intramedullary solid lesion were seen (Figure 2).

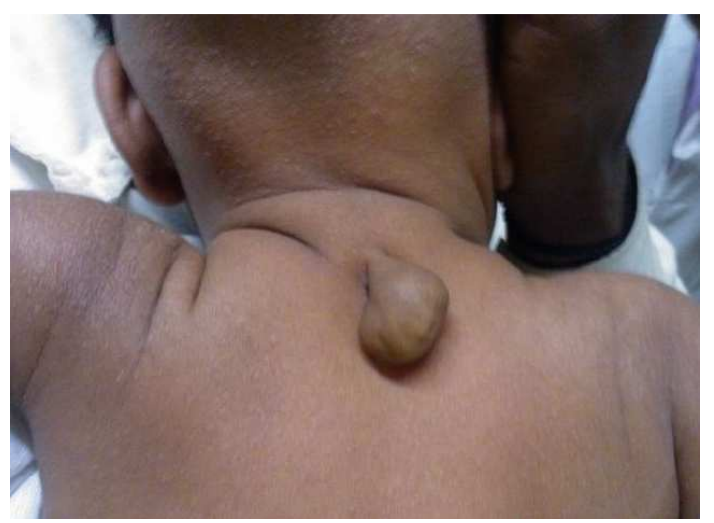

Figure 1 - photographs of patient showing pedicled swelling in cervical region

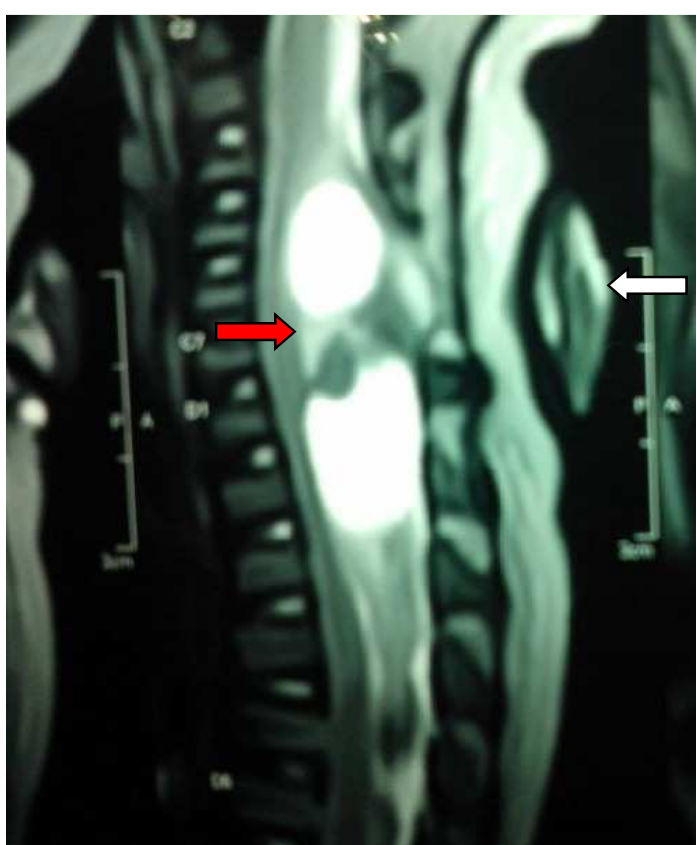

Figure 2 - T2 weighted MRI saggital image showing extracutaneous swelling with deficient posterior arch element at C6-7 (white arrow), with well defined hyperintense intradural cystic lesion and a heterogenous iso to hyperintense intramedullary SOL (red arrow)

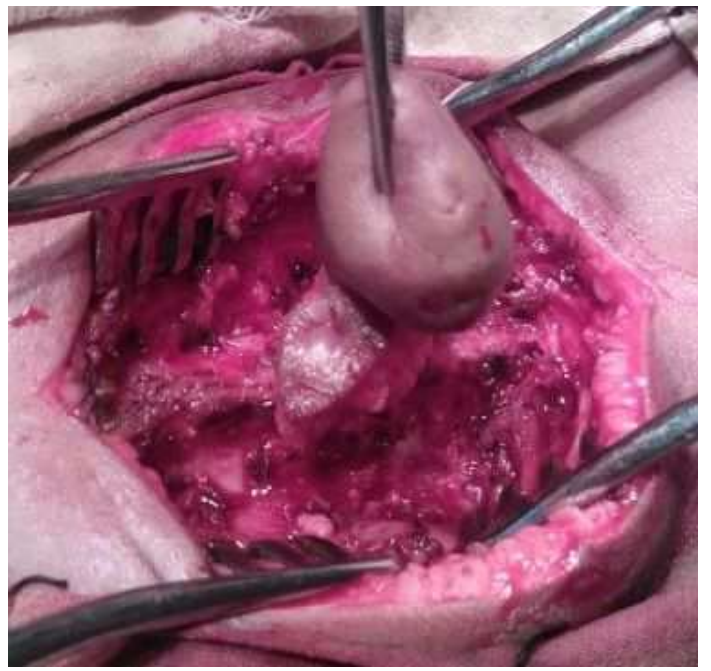

Figure 3 - intraoperative image showing intradural extension of cutaneous lesion through a fibrous tract 
DOI: 10.2478/romneu-2014-0050

C6-C7 Laminectomy with drainage of intradural cystic jelly like component with complete enucleation of intramedullary space occupying lesion containing lipomatous and osseous elements done (Figure 3). Histology was suggestive of mature Teratoma. Post operative recovery was uneventful. At 5 months follow up child is doing well, achieving normal milestones and no neurological deficit.

\section{Discussion}

Teratomas are composed of a mixture of cell types derived from three germ cell layers and can occur at many locations throughout the body. Spinal Teratomas are infrequent and very small proportion of CNS Teratomas occur in the spinal cord, constituting only $0.2-$ $0.5 \%$ of all spinal cord tumors (10). Spinal Teratomas have been reported throughout the spinal axis and the most common sites are lumbar, conus and dorso-lumbar regions. Cervical location is rare.

Hamada et al (6) in their study of 18 intraspinal teratomas found conus medullaris as the most frequent location (70.6\%). Adults were more commonly affected than children. Agrawal et al (1) in their study of 8 cases of spinal teratoma found cervical spine as common a location as lumbar spine (4/8, $50 \%)$. However involvement of cervical spine in pediatric age group was seen in 2 cases only. A similar study by Sharma et al (14) with 27 cases revealed $62.9 \%$ occurrence in childhood with associated dysraphism in $77.7 \%$. However no intramedullary pediatric cervical involvement was found. On searching literature, we could retrieve only eleven patients with cervical intramedullary teratoma in pediatric patients $(1,11)$. Ours is a case of an infant presenting with cervical mature teratoma with associated dysraphism, adding the next in this rare case series.

Several hypotheses have been proposed with regard to the origin of spinal Teratomas. The traditional view is that these lesions are neoplastic and arise from misplaced primordial germ cells into the dorsal midline during their normal migration from the primitive yolk sac to the gonadal ridges $(2,3$, $7,9,15)$. An alternative hypothesis is that these lesions are not neoplastic and are the result of a dysembryogenic mechanism as many of them are associated with a dysraphic state (7). However, Teratomas without associated dysraphic features are also reported. (14)

For diagnosis of spinal Teratomas, conventional X-rays and CT scans have very limited roles and primarily suggests associated bony anomaly, bony changes like vertebral erosions or increased interpedicular distance, associated diastometamyelia or tumors with calcification. MRI is regarded as the gold standard diagnostic technique. Radiologically mixed solid and cystic morphology, fat signal and areas of calcification are seen which appears on MRI as heterogenous iso to hypointense on T1-weighted and heterogenous hyperintense on T2-weighted images. They are non-enhancing on contrast. MRI has localizing value but is not definite for diagnosis. Intramedullary component has been shown to be associated with meningomyelocele or split-cord malformation in few cases (14). Malignant nature is suspected if the lesion is predominantly solid and/or contrast enhancing. 
Histopathologically, Teratomas are composed of the remnants of all 3 germ cell layers $(2,4,5,7,10,12)$. They are classified into 3 types: mature, immature and malignant Teratomas. Mature teratomas contains mature elements of ecto, endo and mesodermal origin. On the other hand, immature Teratomas are aggressive tumors, comprising primitive, undifferentiated components; these tumors tend to recur frequently. Malignant Teratomas are derived from the yolk sac or endoderm sinus, and especially, malignant Teratomas, along with the high levels of serum $\alpha$ fetoprotein, are associated with a poor prognosis $(2,7)$. However, it is essential that elements of the 3 germ cell layers are identified for it to be diagnosed as a spinal teratoma.

Surgery is the treatment of choice, and radical removal of the tumor should be the aim of surgical intervention whenever possible. In children, extensive laminectomies may lead to spinal instability. So laminotomy and laminoplasty should be done. However, complete removal may not always be possible due to the location of tumor. Even a benign tumor can recur due to incomplete removal. Radiotherapy or chemotherapy should be reserved for Teratomas which show an immature or malignant component8. Prognosis is poor for Teratocarcinomas and Teratomas with malignant transformation.

\section{Conclusion}

Teratomas are rare CNS tumor with rarer involvement of cervical intramedullary location in infants. Preoperative diagnosis is difficult and most of the cases diagnosed intraoperatively or on histology. Mature teratoma have good prognosis and timely intervention can prevent further neurological deterioration.

\section{Correspondence}

Dr. Rakesh Kumar

4kh-2, housing board, Shastri Nagar,

Jaipur, Rajasthan, India, 302016.

E-mail: rksingh2226@gmail.com. dr_mittal@hotmail.com

\section{References}

1. Agrawal M, Uppin MS, Patibandla MR, Bhattacharjee S, Panigrahi MK, Saradhi V, Rani JY,Purohit AK, Challa S. Teratomas in central nervous system: A clinicmorphological study with review of literature.Neurology india;58,6:841-846, 2010.

2. Ak H, Ulu MO, Sar M, Albayram S, Aydin S, Uzan M: Adult intra-medullary mature teratoma of the spinal cord: review of the literature illustrated with an unusual example. Acta Neurochir (Wien) 148: 663-669; discussion 669, 2006.

3. Al-Sarraj ST, Parmar D, Dean AF, Phookun G, Bridges LR Clinico-pathological study of seven cases of spinal cord teratoma: Spinal teratoma 251 a possible germ cell origin. Histopathology 32:51-56,1998.

4. Cavazzani P, Ruelle A, Michelozzi G, Andrioli G: Spinal dermoid cysts originating intracranial fat drop causing obstructive hydrocephalus: case report. Surg Neurol 43: 466-469; discussion 469-470, 1995

5. Fernandez-Cornejo VJ, Martinez-Perez M, PoloGarcia LA, Martinez- Lage JF, et al: Cystic mature teratoma of the filum terminale in an adult. Case report and review of the literature. Neurocirugia (Astur) 15:290293, 2004

6. Hamada H, Kurimoto M, Hayashi N, Hirashimma Y, Matsumura N, Endo S. Intramedullary spinal teratoma with spina bifida. Child Nerv Syst;17:109-11, 2001.

7. Koen JL, McLendon RE, George TM Intradural spinal teratoma: evidence for a dysembryogenic origin. Report of four cases. J Neurosurg 89:844-851,1998.

8. Ling YJ, Lai DM, Tsu HC, Lin SM. Primary Intracranial teratocarcinoma with extraneural metastasis- Case Report and review of literature. Acta Neurol Sin;2:332-7. 1993. 
DOI: 10.2478/romneu-2014-0050

9. Makary R, Wolfson D, Dasilva V, Mohammadi A, Shuja S: Intramedullary mature teratoma of the cervical spinal cord at C1-2 associated with occult spinal dysraphism in an adult. J Neurosurg Spine 6: 579-584, 2007

10. Nonomura $\mathrm{Y}$, Miyamoto K, Wada E, Hosoe H, Nishimoto H, Ogura H, et al: Intramedullary teratoma of the spine: report of two adult case. Spinal Cord 40: 40-43, 2002

11. Paterakis KN, Karantanas AH, Barbanis S, Hadjigeorgiou GM, Karavelis A Cervical spinal cord intramedullary teratoma. Clin Neurol Neurosurg 108:514-517. 2006.

12. Poeze M, Herpers M, Tjandra B, Freling G, Beuls E: Intramedullary spinal teratoma presenting with urinary retension: case report and review of the literature. Neurosurgery 45: 379-385, 1999.

13. Sharma MC, Aggarwal M, Ralte $A M$ et al Clinicopathological study of spinal teratomas. A series of 10 cases. J Neurosurg Sci 47:95-100, 2003.

14. Sharma MC, Jain D, Sarkar C, Suri V, Garg A, Singh M, et al. Spinal Teratomas: a clinico-pathological study of 27 patients. Acta Neurochirurgica;151:245-52, 2009

15. Stevens QE, Kattner KA, Chen YH, Rahman MA: Intradural extramedullary mature cystic teratoma, not only a childhood disease.J Spinal Disord Tech 19: 213216,2006 